\title{
A CUBICAL PHOTOMETER FOR STUDYING THE ANGULAR DISTRIBUTION OF SUBMARINE DAYLIGHT
}

\author{
By W. R. G. Atkins, Sc.D., F.R.S. \\ Head of the Department of General Physiology at the Plymouth Laboratory \\ and H. H. Poole, Sc.D. \\ Registrar, Royal Dublin Society
}

The variation in the angular distribution of light at different depths under water has been studied by Pettersson (1938) and his co-workers, Johnson \& Liljequist (1938). Their methods, one of which enables a complete polar diagram of the illumination at any point to be obtained, are, however, scarcely suitable for use on our ship in the comparatively rough water so often experienced off Plymouth, and we felt that some measurements with simpler apparatus might be of interest.

We have accordingly constructed a cubical photometer case in each face of which is a toughened glass window $6 \mathrm{~mm}$. thick and $66 \mathrm{~mm}$. clear aperture, behind which is mounted an "Electrocell" selenium rectifier cell $40 \mathrm{~mm}$. aperture. These cells are connected by a seven-core insulated cable to a set of switches, so that any cell or combination of cells may instantly be connected to the measuring apparatus.

For the latter we have sometimes used a Tinsley box-type light-spot portable galvanometer (resistance Io ohms, sensitivity I6.5 scale divisions per microampere) whose suspended coil had been specially balanced for us by the makers so as to reduce as far as possible the zero shift caused by tilting. A pair of shunt boxes, each with $\times 5$ and $\times$ Io ratios, enabled the galvanometer to be shunted in convenient stages up to $\times 2500$, the effective resistance remaining at Io ohms. This arrangement proved convenient and satisfactory in comparatively calm water, but when there was a considerable swell we found it best to revert to our original potentiometer telephone method, with the Campbell-Freeth zero-resistance circuit (1929, 1934, 1937); the latter method is also quicker in use and less tiring.

The photometer case is made of cast gun-metal, and is about $12.7 \mathrm{~cm}$. each way, or about $15 \mathrm{~cm}$. to the outside of the collars holding the windows. Flanges cast on a pair of opposite vertical edges are drilled near their upper ends to receive the pins of the shackles of the supporting bridle, and also near their lower ends for the attachment of a bridle to carry a sinker, should that prove necessary. The weight of the case, about $17 \mathrm{~kg}$. seems, however, to be sufficient to prevent appreciable tilting under ordinary conditions. The 
cable enters through a gland in one of the upper corners away from the supporting bridle, and in the remaining unoccupied upper corner a hole is drilled and tapped for the attachment of a tube to test the airtightness of the vessel, windows, and cable gland.

As some difficulty was experienced in making the rubber gaskets under the window staunch, the joints were eventually made by heating the gaskets in "Sira" wax, and clamping the windows down on them while still hot. The outer parts of the joints were then filled with Chatterton's compound, which in turn was covered with Berry's compound so as to give a non-adhesive surface. When the vessel had been proved to be airtight the testing tube was replaced by a solid screw plug, which was then sealed with Chatterton's and Berry's compounds. No further leakage troubles occurred down to a depth of $70 \mathrm{~m}$.

Outside each window is mounted a VG 9 Jena colour filter $2 \mathrm{~mm}$. thick covered by an opal-flashed diffusing glass, both being $76 \mathrm{~mm}$. in diameter. As the filter rests on a thin flange of the surrounding metal collar, the window aperture being only $66 \mathrm{~mm}$., there is no danger of light reaching the cell past the edge of the VG 9 filter, which limits the sensitivity mainly to the spectral region between 480 and $580 \mathrm{~m} \mu$. The outer surface of the diffusing glass is approximately flush with the edge of the surrounding brass collar (the glasses being held in place by means of clips) so that each cell is exposed to a complete hemisphere, the six cells measuring the light from the upper and lower hemispheres and four hemispheres with horizontal axes in rectangular azimuths, respectively.

It is often difficult to ensure that azimuths do not change between readings or at different depths, but when the ship is drifting owing to the action of the wind, approximate constancy can be ensured by the simple method of attaching a light horizontal rod with a vane at the end to one of the vertical flanges of the case. If the motion of the case through the water is sufficiently rapid it keeps the vane pointing approximately up-wind, so that the azimuth of each vertical window is nearly constant.

The six photocells were obtained from the makers in one batch, and, before mounting in the case, were tested on the photometer bench for curvature of the light/current characteristic. One of the cells showed appreciably less curvature than the rest, its sensitivity for green light falling by about $5.6 \%$ per milliampere for currents up to $4 \mathrm{~mA}$. This was used for the top window. A second cell, whose curvature correction was much larger-about II.7\% per mA. was used for the lower cell to measure the small amount of light passing upwards. The corrections for the other four were sufficiently close to $7.0 \%$ per $\mathrm{mA}$. for this value to be used for each of them. They were mounted behind the side windows. Unfortunately, there seems to be little doubt that while the weak-light sensitivity of these selenium cells may remain approximately constant their curvature correction may increase with time, thus causing their sensitivity for strong light to decrease very considerably. 
Some cells seem to be immune to this effect, and it appears to be small or absent in our standard Weston, but all the cells in this photometer showed it strongly. When tested against our standard Weston cell in May and June, 1939, 7 months after the marine measurements Series C I to C 9, in daylight whose intensity was varied by means of additional opal glasses, they showed corrections ranging from I2 to $42 \%$ per mA. the changes in the weak-light sensitivity being small.

Fortunately the cell used to measure the downward vertical light still showed much the smallest correction, and these corrections are not very important in the weak light generally experienced by the other cells under water. It seems improbable, therefore, that any change of correction that may have occurred during the period of 7 or 8 weeks between the original standardizations and the dates of Series C I to C 9 could have had any important effect on the results. For Series C Io, obtained within a few days of the later determinations of "curvature" the revised corrections were used.

Further work on the increase of correction with time is desirable, and also on an effect that we came across during the bench tests, namely that the curvature depends on the colour of the light, being much greater for all cells with deep red light. This is probably due to increased leakage of current in bright light owing to the photo-conductivity of selenium, which has a maximum of sensitivity near the red end of the visible spectrum.

The relative sensitivities of the bare cells for weak light were found during the initial bench tests, but as differences might also occur in the filters, or diffusing glasses, the relative sensitivities of the cells as mounted in the case were found by daylight comparisons. A number of comparisons were also made between the top cell, as mounted, and our standard Weston mounted behind a VG 2 filter and opal glass (the VG 2 and VG 9 filters are very similar). These comparisons revealed certain irregularities, some of the ratios obtained differing by some 10 \% from the mean value. Comparisons made under the best conditions were, however, considerably closer, and by taking the mean it is probable that the error in the percentage illuminations due to this cause are not very serious. In one instance (Series C 6) the percentages have been reduced by $5 \%$ in order to reduce the value found just above the water surface to Ioo. Such errors in the percentages would be common to all the percentages in a given series (unless the errors were due to faulty curvature correction) and so would not affect the values found for the extinction coefficients. It seems possible that the intensities as measured by the deck cell were low in this series, since it was found that the gimbals mounting of the deck photometer was not functioning freely. This mounting has since been overhauled and an additional lead casting added so that the restoring force has been much increased; a more nearly level position is thus maintained.

In view of the irregularities in the behaviour of the cells used in this photometer the results given below are likely to be inferior in accuracy to 
those obtained, for vertical light only, with our Weston cell photometer, but it seems most unlikely that any errors which may occur are large enough to invalidate the general conclusions reached.

Only a few series of determinations have been made as yet, and in some of them the absence of drift allowed the photometer to rotate, and rendered it difficult to interpret the readings of the side cells. Thus in series C I, the results of which are shown in Table I, the ship was anchored inside Plymouth breakwater, and there evidently was not sufficient tide to keep the photometer steady. As there was bright sunlight, the light under water was very highly directive, so that rotation of the photometer between readings rendered the results obtained with the side cells quite unreliable, and they have been omitted from the table, which only shows the results for the top and bottom cells, which of course are unaffected by rotation.

\section{TABLE I}

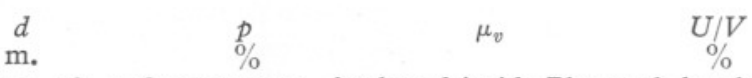

SERIES C I. 20. x. 38, I.I8 to 3.4 p.m. Anchored inside Plymouth breakwater. Sun and high wispy clouds. Wind fresh, E. Secchi disk seen to $7 \mathrm{~m}$.

$\begin{array}{cccc}\text { A.W. } & 87 & \ldots & 9.9 \\ \text { I } & 56 & \ldots & 5.8 \\ 5 & 23.3 & 0.219 & 5.2 \\ \text { I0 } & 9.0 & 0.190 & 5.5 \\ \text { I5 } & 3.45 & 0.192 & 8.5 \\ \text { A.W. } & 89.5 & \ldots & 8.2\end{array}$

Here $d$ is the depth in metres, A.W. meaning that the photometer was suspended about $\mathrm{I} .5 \mathrm{~m}$. above the surface, in a position where some shading by the ship may have occurred. $p$ is the percentage of the surface illumination, the latter being measured by our standard Weston cell with green VG 2 filter mounted on the roof of the deckhouse. $\mu_{v}$ is the vertical extinction coefficient for the depth interval between that opposite which it is printed and that next above. $U / V$ is the ratio of the upward to the downward illumination, expressed as a percentage.

It will be noted that above water the mean value of $U / V$ is near $9 \%$; at intermediate depths it is about $5.5 \%$; and at $15 \mathrm{~m}$. reflection off the bottom, which was not far below, had raised it to $8.5 \%$. The extinction coefficient, near $0 \cdot 20$, is considerably higher than that found out at sea a few days later, and we will see that in the clearer water the percentage of back-scattered light is considerably reduced. Clarke (I936) also found $4-6 \%$ for similar inshore water at Provincetown Harbour and Buzzards Bay.

If the sun is not shining the differences between the readings of the four side cells are far less marked, though it is not uncommon for one or two of them to give values some $50 \%$ higher than the others. This may partly be due to the greater brightness commonly found in the southern part of the sky, and partly to the large area of water darkened by the shadow of the ship, 
but unless the drift is sufficiently rapid to keep the photometer azimuth constant it is hard to disentangle the two effects.

It is probably best under these circumstances to read the sum of the currents through the four cells, remembering when correcting for curvature that, on the average only one-quarter of the current flows through each cell. This involves an under-correction, as the more strongly illuminated cells passing the larger currents should have larger correction factors applied to them. Moreover, the effective resistance of the galvanometer is increased, which would also slightly raise the factor. The error is not likely to be serious, however, unless the sun is shining, when each cell should be treated separately.

It is evident that, in the absence of direct sunlight, the mean horizontal illumination (as measured by a photometer with a plane vertical window set successively in all azimuths) is approximately equal to one-quarter of the sum of the four horizontal readings in rectangular azimuths. It would not, however, give a true picture of the average obliquity if we were to measure it by the ratio of this mean to the vertical illumination on the upper horizontal window. Almost all the light comes from above, the percentage of backscattered light being generally from 2 to 5, and every oblique ray, no matter what its azimuth, contributes to the vertical illumination, whereas about half of them will fail to contribute to the horizontal illumination on a vertical window set in any given azimuth.

If we could replace our photometer having one horizontal and four vertical windows, each of area $A$ suppose, by one, with a vertical cylindrical surface, area $\pi A$, to measure the horizontal light, it would obviously have an effective vertical area $A$ to measure the horizontal component of a single ray in any azimuth. Thus the ratio of the light falling on the cylindrical surface to that on the horizontal plane surface would give the tangent of the obliquity of the ray. The actual illumination contains rays of all azimuths and obliquities, but still the mean value of the ratio would be the mean tangent of the obliquity, or we may say without serious error, the tangent of the mean obliquity. For any distribution not including a comparatively narrow beam, as would be produced by direct sunlight, the average efficiency per square centimetre of our four vertical windows would be very close to that of the cylindrical surface, thus, as their area is $4 / \pi$ times as large, we should take $\pi / 4$ times the sum of their readings as a measure of the total horizontal component of the light. The ratio of this to the vertical illumination gives the mean value of the tangent of the obliquity. It is worth noting that in air under a uniform hemispherical sky this ratio would have the value $\pi / 2$, i.e. $\mathrm{I} \cdot 57$, corresponding to an obliquity of $58^{\circ}$, i.e. an altitude of $32^{\circ} .^{\star}$ Beneath a smooth water surface the combined effects of refraction and of enhanced surface reflection of oblique rays greatly reduce the ratio, which falls to 0.60 , corresponding to an obliquity of $3 \mathrm{I}^{\circ}$, so

* In view of the fact that the mean value of $H / V$ is used as a measure of the angular distribution under water it seems to be more natural to describe this by the obliquity (i.e. the angle between the light and the vertical) rather than by the complementary angle of altitude, although we have hitherto used the latter for both aerial and submarine illumination. 
we may take this angle as the average obliquity to be expected under a smooth water surface with a uniform sky. This obliquity is the same as that for a ray of sunlight with the sun at a zenith distance $43^{\circ} \cdot 4$, i.e. at an altitude of $46^{\circ} \cdot 6$, so for altitudes near that value the presence of direct sunlight should not have much effect on the average under-water obliquity.

Table II shows the results of three series obtained with an overcast sky and very light breeze near stations $\mathrm{L}_{5}, \mathrm{~L}_{4}$, and $\mathrm{L}_{3}$, situated 9,5 , and I. 5 miles south-south-west of Plymouth breakwater, respectively. The water surface was glassy, and the light dull, falling to about 3.7 kilolux at the end of series $\mathrm{C}_{4}$ (as measured with standard Weston without colour filter), and becoming very weak by the time the $\mathrm{C}_{5}$ measurements were made. These readings were made with the galvanometer. $H / V$ is the ratio of the "total horizontal component" (as already defined) to the vertical component of the light, and $\theta=\tan ^{-1} H / V$ is the mean angle of obliquity, namely the angle with the vertical. The other symbols have the same meaning as before, and all measurements refer to green light.

\section{TABLE II}

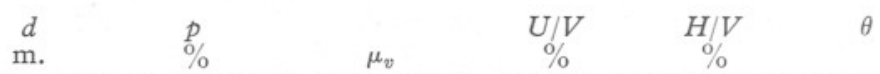

SERIES C 3, 25. x. 38, I I.27 a.m. to I2.45 p.m. At L 5, depth by sounding 56 m. Secchi disk visible to $15.5 \mathrm{~m}$.

Means

67.5
39.5
22.4
13.4
4.8
0.94
0.18

0.
0.133
0.114
0.103
0.103
0.109
0.110
0.110

$2.36^{\star}$
3.08
3.25
3.03
3.08
2.67
$5.6^{\star}$
3.02

$\begin{array}{ll}58^{\star} & 30^{\circ} \\ 71 & 35^{\circ} \\ 77 & 38^{\circ} \\ 78 & 38^{\circ} \\ 72 & 36^{\circ} \\ 70 & 35^{\circ} \\ 70 & 35^{\circ} \\ 73 & 36^{\circ}\end{array}$

SerIes C 4, 25. x. 38, 2.38 to 3.5 p.m. At L 4, Secchi disk visible to I I m.

Means

56.5
20.6
6.05
1.87
0.62

O.II2
O.I22
O.II7
O.IIO
O.II

$3.17^{\star}$
3.29
3.31
2.91
$\cdots$
3.17

$71^{\star}$
84
85
76
77
80

$$
\begin{aligned}
& 35^{\circ} \star \\
& 40^{\circ} \\
& 40^{\circ} \\
& 37^{\circ} \\
& 37^{\circ}
\end{aligned}
$$

\begin{tabular}{|c|c|c|c|c|c|c|}
\hline & I & 62 & . & $2 \cdot 73^{\star}$ & $64^{\star}$ & $33^{\circ \star}$ \\
\hline & 5 & $35 \cdot 5$ & 0.139 & 3.07 & 70 & $35^{\circ}$ \\
\hline & IO & 18.6 & 0.129 & 3.45 & 78 & $38^{\circ}$ \\
\hline & 20 & $5 \cdot I$ & 0.129 & 3.85 & 84 & $40^{\circ}$ \\
\hline & 30 & $I \cdot 23$ & 0.142 & $3.0 *$ & 90 & $42^{\circ}$ \\
\hline Means & . & 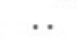 & 0.135 & 3.45 & 80 & $39^{\circ}$ \\
\hline
\end{tabular}

SERIES C 5, 25. x. 38, 3.45 to 4.6 p.m. At L 3 , Secchi disk visible to I2.5 m.

It is evident that on this day the water was fairly clear and very uniform, the opacity increasing slightly as one moved inshore. The percentage of upward light remained close to 3 throughout, neglecting a low reading at 
I $\mathrm{m}$. and a high reading near the bottom, both in series $\mathrm{C}_{3}$. The former is probably not very reliable, as readings so near the surface are difficult, and the latter is almost certainly raised by reflection off the bottom. The average obliquity was in general rather greater than that for the ideal case of smooth water and uniform sky. This was to be expected, as the sky is usually brighter at comparatively low altitudes, especially with the low, though completely obscured, sun of an October afternoon, and such waves as occurred in the comparatively smooth surface would further increase the average obliquity. It is somewhat surprising, however, that there is no evidence of a decrease of average obliquity with depth, due to enhanced absorption of oblique rays. Even in this clear water scattering appears to have been sufficient to maintain or in some cases even increase, the obliquity. The $U / V$ ratio was found by us previously to be as low as I. 3 and $\mathrm{I} \cdot 8 \%$ (I928, I933) with potassium cells (blue sensitive). Utterback (I936) reports about I \% for green (5300 A.) and $2 \%$ for blue (4800 A.).

When the sun is shining the differences between the readings of the side cells become very large, and it is no longer sufficient merely to take the sum of their readings. Under these circumstances, as has been pointed out, the disentangling of the results for horizontal light becomes difficult and unsatisfactory unless there is sufficient drift to keep the orientation of the photometer approximately constant. This was the case on October 26 at International Station E I 20 miles south-south-west of Plymouth breakwater, when series C 6 was obtained, the results being set out in Table III. With the sun shining and the ship lying beam on to the wind, her head is always turned in whichever direction is most remote from the sun. Thus the photometer over the stern is safe from all shading of direct light, and as this forms the greater part of the total illumination the effect of the ship's shadow is much reduced. It affects chiefly one of the two side cells turned away from the sun, and on this we can base an attempt to disentangle the relative effects of sunlight and diffuse light from the readings of the four side cells.

Thus on October 26 I938 there was a strong north-west wind and rising sea. The ship lay with her head to the north-east, so that the sun, whose mean bearing during the series must have been about south-south-west to south-west by south (Magnetic), was astern and somewhat to starboard. The photometer vane in line with an edge between two cells presumably pointed upwind, i.e. north-west. This would bring the four side cells, which we designate $A, B, C$, and $D$, into positions facing approximately north, east, south, and west, respectively. We should expect that $A$ would give the lowest reading, as it was the most remote from the sun, and partly faced the ship and the area of darkened water along her port side. $B$ was also partly directed toward the ship, but on her starboard side where there was no shading of direct sunlight. $C$ and $D$ must both have received direct sunlight, and were entirely unshaded by the ship.

These expectations were, in the main, realized, though on two occasions- 
at 20 and at $70 \mathrm{~m}$.- the photometer appears to have swung round slightly so that $B$ and not $D$ received a share of the sunlight, and on the second of these with the photometer close to the bottom $D$ actually received slightly less light than $A$. In working out the results we have assumed that the cell giving the lowest reading ( $A$ for all depths except $70 \mathrm{~m}$.) was affected by shading, that the cell giving the reading lowest but one ( $B$ for most depths, $D$ for $20 \mathrm{~m}$., $A$ for $70 \mathrm{~m}$.) might be taken as a measure of the diffuse horizontal light, and that the excesses of the readings of the remaining two cells ( $C$ and either $D$ or $B$ ) above this value were due to the horizontal component of the direct sunlight. Thus if $c$ is the reading of cell $C$ (always the greatest), and so on, and taking $b$ as the diffuse light we have $c-b$ for the horizontal sunlight on $C$, and $d-b$ for that on $D$. Hence, if $H_{s}$ is the horizontal component of the sunlight making an azimuthal angle $\phi$ with the normal to $C$, we have $c-b=H_{s} \cos \phi$, and $d-b=H_{s} \sin \phi$ hence $\tan \phi=\frac{d-b}{c-b}$. Hence we can find $\phi$, and so $H_{s}$, the horizontal component of the sunlight as would be measured by a vertical window set in azimuth perpendicular to that of the rays. A cylindrical photometer area of curved receiving surface $\pi A$ would only offer an area $A$ to this directed light, but its area for the diffuse light would be $\pi A$, so that $H_{d}$, the total horizontal component of the diffuse light, is $\pi b$, and $H$, the total horizontal component of all the light, is $H_{s}+H_{d}$.

\section{TABLE III}

$$
\begin{array}{ccccccc}
d & p & \text { U/V } & & H / V \\
\mathrm{~m} . & \% & \mu_{v} & \% & H_{s} / H_{d} & \% & \theta
\end{array}
$$

SERIES C 6, 26. x. $38,12.52$ to I.5I p.m. Sun's altitude $26-22^{\circ}$, mean $24^{\circ}$. Obliquity of sun's rays beneath smooth surface $42-44^{\circ}$, mean $43^{\circ}$. Obliquity for diffuse sky light $31^{\circ}$. At Station E I, depth by sounding $7 \mathrm{I} \mathrm{m}$. Strong north-west wind and swell becoming heavy. Clear sun and blue sky.

\begin{tabular}{rccccccc} 
& I & 95.5 & $\ldots$ & $2.15^{\star}$ & 2.30 & $63.55^{\star}$ & $32^{\circ}$ \\
& 5 & 48.5 & 0.170 & 2.68 & 2.07 & 88.5 & $42^{\circ}$ \\
& IO & 25.8 & 0.126 & 2.98 & 0.67 & 88.5 & $42^{\circ}$ \\
& 20 & 6.8 & 0.133 & 3.28 & 0.805 & $118.5{ }^{\star}$ & $50^{\circ}$ \\
& 40 & 0.96 & 0.097 & 3.34 & 0.254 & 79.5 & $38^{\circ}$ \\
& 55 & 0.183 & 0.110 & 2.60 & 0.178 & 77.5 & $38^{\circ}$ \\
\multirow{2}{*}{ Means } & 70 & $0.04 \mathrm{I}$ & 0.100 & $3.75^{\star}$ & 0.063 & 79.5 & $38^{\circ}$ \\
& $\ldots$ & $\ldots$ & 0.112 & 2.98 & $\ldots$ & 83 & $40^{\circ}$
\end{tabular}

Series C IO, 30. v. 39 , noon to 2 p.m. Sun's altitude $62-53^{\circ}$, mean $58^{\circ}$. Obliquity beneath smooth water surface $20-27^{\circ}$, mean $23^{\circ}$. At Station $\mathrm{L}_{4}$, depth about $50 \mathrm{~m}$. Strong eastsouth-east wind, heavy swell with breaking waves. Clear sun and unclouded sky.

\begin{tabular}{|c|c|c|c|c|c|c|c|}
\hline & I & 59 & $\cdots$ & $I \cdot 9 I^{*}$ & $3 \cdot 39$ & $64^{\star}$ & $33^{\circ} \star$ \\
\hline & 5 & 42.5 & 0.082 & 2.02 & 3.48 & $7 I$ & $35^{\circ}$ \\
\hline & IO & 30.5 & 0.065 & $I \cdot 80$ & $2 \cdot 21$ & 77 & $37^{\circ}$ \\
\hline & I5 & 23.5 & 0.052 & $I \cdot 89$ & I.94 & 69 & $35^{\circ}$ \\
\hline & 20 & $I 6 \cdot I$ & 0.075 & 2.07 & $I \cdot 70$ & 76 & $37^{\circ}$ \\
\hline & 30 & 5.95 & 0.099 & $2 \cdot 72$ & I. 59 & 90 & $42^{\circ}$ \\
\hline & 40 & $2 \cdot 52$ & 0.086 & $4.05^{\star}$ & 0.94 & 89 & $42^{\circ}$ \\
\hline Means & .. & $\ldots$ & 0.076 & $2 \cdot 10$ & . & 79 & $38^{\circ}$ \\
\hline
\end{tabular}


We cannot measure separately the vertical components of the sunlight and diffuse light, since we cannot perform shading tests under water. It would seem, therefore, that the most convenient method of expressing the results at any depth is to give as before the value of $H / V$ and also the value of $H_{s} / H_{d}$, the latter giving a measure of the persistence of direct sunlight at different depths, and hence of the scattering.

The table also shows the results obtained at $\mathrm{L}_{4}$ on May 30 1939, with a cloudless sky, high sun, fresh wind and heavy swell with breaking waves. As the wind on this day was east-south-east cell $A$ always received most of the direct sunlight.

With sunlight and rough water surface the readings at $\mathrm{I} \mathrm{m}$. must have been rather unreliable, so that no special significance need be attached to the very low surface loss in series C 6 nor to the rather high loss indicated in C ro. The readings at $20 \mathrm{~m}$. in series $\mathrm{C} 6$ are somewhat anomalous and those at $70 \mathrm{~m}$. show the effects of reflection off the bottom. In finding the averages shown for each series the readings marked have been disregarded.

It would seem from the above figures that when the surface is rough, at least, the presence of either low or high sunlight makes little difference in the average obliquity of the light under water as compared with that found in the series with overcast sky. There is no evidence of reduction of average obliquity with depth; in fact in C Io it apparently increased somewhat, which may be connected with the increase in the extinction coefficient found below $20 \mathrm{~m}$.

The most remarkable feature of series $\mathrm{C}$ Io is the exceedingly clear water in which it was carried out. The average extinction coefficient from I to $20 \mathrm{~m}$. was only 0.068 which is rather smaller than any value that we have previously found for such an interval of depth. Below $20 \mathrm{~m}$. there was a slight increase. It is possible that the depths may have been slightly over-estimated, as owing to the rapid drift the supporting wire made an angle of some $15^{\circ}$ with the vertical when the photometer was at $40 \mathrm{~m}$. This would cause the depth to be over-estimated by some 2 or $3 \%$, with a corresponding reduction in the value of $\mu_{v}$. At the smaller depths, where the lowest values of $\mu_{v}$ were obtained, the relative error would be less, as the wire would be more nearly vertical.

This very clear water was similar to that found by Utterback \& Jorgensen (I934) in the North Pacific. It was accompanied by a low value for the upward light, and the increase in this near the lower limit of the series may be due to the slight increase found in the opacity, since the bottom was too far below to reflect an appreciable amount of light. The low value of $\mu_{v}$ recorded above may be compared with that given by Oster \& Clarke (1935), 0.049, for the Sargasso Sea, and Clarke's (1938) even lower value, 0.038, for the Cayman Sea, the most transparent part of the ocean as yet examined. 


\section{SUMMARY AND CONCLUSIONS}

Preliminary observations have been made in the English Channel off Plymouth on the average obliquity of illumination under water, and on the relative intensity of light reflected upwards at various depths, the readings being made with a cubical photometer containing six "Electrocell" selenium rectifier cells mounted behind opal glasses and Jena VG 9 (green) filters. The cells measured the light of wave-lengths about $480-580 \mathrm{~m} \mu$ falling on upwardand on downward-turned horizontal surfaces, and on four vertical surfaces in rectangular azimuths.

The average angle with the vertical or of obliquity was from 36 to $40^{\circ}$, and no significant difference could be detected between that for smooth sea and overcast sky, and that for rough sea and either high or low sun. Figures for smooth sea and sunlight are more difficult to obtain, as in the absence of drift due to wind the photometer may rotate.

No decrease in average obliquity with depth was found, in some cases there was evidence of a slight increase. This is in accordance with our previous results, and accords well with the constancy of extinction coefficient so often found throughout a series. It is not, however, in agreement with the careful work of Johnson \& Liljequist, so further determinations would seem to be desirable.

The percentage of the light which was scattered back so as to fall on a downward-turned surface varied from 5.5 for comparatively opaque water (extinction coefficient $0 \cdot 20$ ) inside Plymouth breakwater, to $2 \cdot \mathrm{I}$ for very clear water (extinction coefficient 0.076 ) some miles off at sea. The presence or absence of sunlight had little effect, values close to 3.0 being obtained with and without sun for water having a coefficient close to O.IIO.

\section{REFERENCES}

Atkins, W. R. G. \& Poole, H. H., I933. The photo-electric measurement of the penetration of light of various wave-lengths into the sea and the physiological bearing of the results. Philos. Trans. Roy. Soc. London, B, Vol. 222, pp. 129-64.

Clarke, G. L., I936. Light penetration in the western North Atlantic and its application to biological problems. Cons. Int. Explor. Mer. Rapp. Proc. Verb., Vol. IOI, Pt. 2, No. 3, I4 pp.

- 1938. Light penetration in the Gulf of Mexico. Fourn. Marine Research, Vol. I, pp. 85-94.

Johnson, Nils G. \& Liljequist, Gösta, I938. On the angular distribution of submarine daylight and on the total submarine illumination. Svenska Hydrogr. Biol. Komm. Skr., Ny series: Hydrogr. xiv, I5 pp.

Oster, R. H. \& Clarke, G. L., I935. The penetration of red, green and violet components of daylight into Atlantic waters. Fourn. Opt. Soc. Amer., Vol. 25, pp. 84-9I.

Pettersson, H., I938. Measurements of the angular distribution of submarine light. Cons. Int. Explor. Mer. Rapp. Proc. Verb., Vol. 108, Pt. 2, No. 2, 6 pp.

Poole, H. H. \& Atkins, W. R. G., I928. Further photo-electric measurements of the penetration of light into sea water. Fourn. Mar. Biol. Assoc., Vol. xv, pp. 455-83. 
Poole, H. H. \& Atkins, W. R. G., I929. Photo-electric measurements of submarine illumination throughout the year. Fourn. Mar. Biol. Assoc., Vol. xvI, pp. 297-324. - 1934. The measurement of the current generated by rectifier photo-cells. Sci. Proc. Roy. Dublin Soc., Vol. 21, No. 13, pp. I33-9.

- 1937. The penetration into the sea of light of various wave-lengths as measured by emission or rectifier photo-electric cells. Proc. Roy. Soc. London, B, No. 83I, Vol. I23, pp. I5I-65.

UtTerback, C. L. \& JoRgensen, W., I934. Absorption of daylight in the North Pacific Ocean. Fourn. Cons. Int. Explor. Mer. Rapp. Proc. Verb., Vol. Ix, No. 2, pp. 197-209.

UtTERBACK, C. L., I936. Spectral bands of submarine solar radiation in the North Pacific and adjacent inshore waters. Cons. Int. Explor. Mer. Rapp. Proc. Verb., Vol. Ior, Pt. 2, No. 4, pp. I5. 